The published version of this article was published in Nature Climate Change on 7 October 2019 and is available at https://doi.org/10.1038/s41558-019-0589-3

\title{
Saxitoxin and tetrodotoxin bioavailability increases in future oceans
}

\author{
Roggatz, C.C. ${ }^{12^{*}}$, Fletcher, N. ${ }^{2}$, Benoit, D.M. ${ }^{3}$, Algar, A.C. ${ }^{4}$, Doroff, A. ${ }^{5}$, Wright, B. ${ }^{6}$, Wollenberg \\ Valero, K.C. ${ }^{2}$, and Hardege, J.D. ${ }^{2}$
}

${ }^{1}$ Energy and Environment Institute, University of Hull, Cottingham Road, Hull, HU6 7RX, UK

${ }^{2}$ Department of Biological and Marine Sciences, University of Hull, Cottingham Road, Hull, HU6 7RX, UK

${ }^{3}$ Department of Physics and Mathematics, E.A. Milne Centre for Astrophysics \& G.W. Gray Centre for Advanced Materials, University of Hull, Cottingham Road, Hull, HU6 7RX, UK

${ }^{4}$ School of Geography, University of Nottingham, University Park, Nottingham NG7 2RD, UK

${ }^{5}$ South Slough National Estuarine Research Reserve, Seven Devils Road, Charleston, OR 97420, USA

${ }^{6}$ Aleutian Pribilof Islands Association, E. International Airport Rd., Anchorage, AK 99518, USA

*Corresponding author: C.Roggatz@hull.ac.uk, +44 (0)1482 462361

Keywords: neurotoxins, ocean acidification, $\mathrm{pH}$-dependent toxicity, geospatial toxicity maps, chemically mediated behaviour.

Increasing atmospheric $\mathrm{CO}_{2}$ levels are largely absorbed by the ocean, decreasing surface water $\mathrm{pH}^{1}$. In combination with increasing ocean temperatures, these changes have been identified as a major sustainability threat to future marine life $^{2}$. Interactions between marine organisms are known to depend on biomolecules, however the influence of oceanic $\mathrm{pH}$ on their bioavailability and functionality remains unexplored. Here we show that global change significantly impacts two ecological keystone molecules ${ }^{3}$ in the ocean, the paralytic neurotoxins saxitoxin (STX) and tetrodotoxin (TTX). Increasing temperatures and declining $\mathrm{pH}$ increase the abundance of their toxic forms in the water. Our geospatial global model predicts where this increased toxicity could intensify the devastating impact of harmful algal blooms, for example through an increased incidence of paralytic shellfish poisoning (PSP). Calculating future saxitoxin toxicity levels in Alaskan clams, Saxidomus gigantea, shows critical exceedance of limits safe for consumption. Our findings for TTX and STX exemplify potential consequences of changing $\mathrm{pH}$ and temperature on chemicals dissolved in the sea. This reveals major implications not only for ecotoxicology, but also for chemical signals mediating species interactions such as foraging, reproduction, or predation in the ocean with unexplored consequences for ecosystem stability and ecosystem services. 
Climate change is not only increasing oceanic water temperatures, but also decreasing seawater $\mathrm{pH}$ as increasing atmospheric carbon dioxide $\left(\mathrm{CO}_{2}\right)$ is absorbed by the ocean ${ }^{1,4}$. The change occurs through the formation of carbonic acid, which further dissociates into $\mathrm{HCO}_{3}{ }^{-}$and protons, leading to a predicted drop of up to $0.4 \mathrm{pH}$ units by 2100 , reaching mean $\mathrm{pH}$ levels of 7.7 in a high-emission scenario (Representative Concentration Pathway, RCP8.5) ${ }^{1}$. In some coastal areas, seawater conditions of $\mathrm{pH} 7.2$ are already observed temporarily ${ }^{5}$ and are predicted to decrease further in the future. Environmental change presents a significant challenge to marine organisms at physiological, ecological, as well as behavioural level. The current rate of $\mathrm{pH}$ change already impacts marine organisms' calcification ${ }^{6}$, physiology and fitness ${ }^{7}$. Interference with acid-base balance and the control of neurotransmitter function have been proposed as possible mechanisms by which ocean acidification could disrupt olfactory-mediated behaviours ${ }^{8}$. But there is also increasing evidence that a direct impact of $\mathrm{pH}$ on information-carrying signalling cues and their corresponding receptors could cause info-disruption in marine chemical communication ${ }^{9,10}$.

Marine organisms use a wide range of biomolecules to locate food and mating partners or to deter predators $^{11}$. Many of these molecules also possess functional chemical groups that are sensitive to $\mathrm{pH}$ including hydroxyl-, carbonyl-, carboxyl-, amine-, phosphate- or sulfide-groups. Thus, changes in pH in future oceans can potentially alter a range of biological functions ${ }^{2,9}$. Among these, saxitoxin and tetrodotoxin have a large variety of ecological functions at very low effective concentrations ${ }^{12,13}$. They serve as antipredator defence through accumulation in cells, skin, tissue, eggs and oocytes in dinoflagellates, snails, ribbon worms, blue-ring octopus and pufferfish, or can be used as offensive weapon upon prey organisms ${ }^{13,14}$. Both toxins are released into the environment for communication purposes, e.g., as an attractant pheromone for male pufferfish ${ }^{14}$, or as sex-pheromone during the gametogenesis of Alexandrium $s p .^{15}$, a dinoflagellate causing harmful algal blooms (HABs). High levels of STX usually contained within the algal cells are further released upon cell lysis at bloom-termination ${ }^{16}$. Predicted changes in climate are expected to further increase the duration, distribution and severity of $\mathrm{HABs}^{17}$, while ocean acidification has been directly shown to give toxic microalgae an advantage during a normal plankton bloom, resulting in their mass development and formation of $\mathrm{HABs}^{18}$. STX produced by Alexandrium sp. often accumulates in the food chain, causing paralytic shellfish poisoning (PSP) and major die-offs of fish, benthic invertebrates, and marine mammals ${ }^{19,20}$, with implications for marine ecosystems as well as global food security. HABs can also cause harm to humans, including direct human mortalities, mainly due to ingesting toxic seafood, direct skin contact with contaminated water or inhaling aerosolized biotoxins ${ }^{21}$. By blocking ion channels in nerves and muscles, STX and TTX cause partial or fatal paralysis ${ }^{21}$.

Both neurotoxins, STX and TTX, contain functional chemical groups that are impacted by $\mathrm{pH}^{22,23}$. Their protonated forms, which are more prevalent in acidified conditions, are known to possess a more effective inhibitory capacity for ion channels ${ }^{24}$. Once protonated, there are strong electrostatic interactions of the toxins' hydroxyl and positively charged 7,8,9-guanidinium groups with the negatively charged carboxylic side chains of the ion channels' extracellular selectivity filter site ${ }^{24,25}$. These lead to a full blockage of 
voltage-gated sodium $(\mathrm{NaV})$ channels in nerves and muscles ${ }^{13}$, L-type $\mathrm{Ca}^{2+}$ channels ${ }^{24}$ and voltage-gated potassium channels ${ }^{13}$. In comparison to their non- or partly protonated counterparts, the fully protonated forms of STX and TTX foster an even stronger electrostatic interaction with the channels, preventing ion flux, and are therefore more potent in their toxicity ${ }^{24}$. The longer TTX/STX is bound, the more damaging the effect on nerve and muscle fibres ${ }^{24}$. The effects of $\mathrm{pH}$ on STX and TTX toxicity have been shown in the laboratory, but have not been translated into an ecological context, nor quantified for global future ocean models.

Here we calculate environmentally-mediated differences in protonation states of both TTX and STX and some of their derivatives in the context of published oceanic climate change scenarios ${ }^{1}$, visualise their toxicity-enhancing electrostatic differences and map their global abundance today and in future oceans.

We calculated the relative proportion of each protonation state in comparison to other states present in solution based on the $\mathrm{p} K_{a}$ constants of the ionisable groups using the Henderson-Hasselbalch equation and incorporated effects of water temperature as a $\mathrm{p} K_{a}$ influencing factor. The results were visualised across the $\mathrm{pH}$ range (Fig. 1) and compared between today's average sea surface $\mathrm{pH}(\mathrm{pH} 8.1)$, future oceanic conditions $(\mathrm{pH} 7.7)^{1}$ and temporary coastal scenarios $(\mathrm{pH} 7.2)^{5}$ (Table 1). The protonated toxic form of tetrodotoxin will increase by $6.2 \%$ under the RCP8.5 scenario ( $\mathrm{pH} 7.7$, sea surface temperature (SST) $20.1^{\circ} \mathrm{C}$ ), whilst the presence of the most toxic saxitoxin state, with protonated 1,2,3- and 7,8,9-guanidinium groups, will increase by $15.5 \%$ (Table 1$)$. Taking salt $(\mathrm{KCl})$ into account alters the change towards the fully protonated form of STX to $13.0 \%$ (for details see Methods). Protonated and therefore toxic forms of saxitoxin derivatives, for example neoSTX and dcSTX, also increase by $9 \%$ and $17 \%$ (see Table 1 ).

To investigate the electrostatic properties of the protonated toxin forms causing enhanced toxicity, we computed lowest energy models of current and future TTX and STX protonation states using our recently developed and experimentally verified quantum chemical approach ${ }^{26}$. We calculated the molecular electrostatic potential (MEP) without and with the presence of water molecules (see also Supplementary Information). We visualised the charge distribution of each conformer using their MEP mapped on an electron density iso-surface to highlight molecular differences. The three-dimensional conformation of TTX and STX does not change significantly upon protonation (root mean square deviation (RMSD) of carbon atoms between protonated and non-protonated forms is $\pm 0.013 \AA$ ). However, the $\mathrm{TTX}^{0}$ and $\mathrm{STX}^{+}$ protonation states show a distinct charge separation while the fully protonated states $\mathrm{TTX}^{+}$and $\mathrm{STX}^{2+}$ are overall more positively charged (Fig. 1). The most significant changes in charge from negative to positive can be observed directly at the groups subject to protonation: the oxygen bound to C-10 in TTX and the 7,8,9-guanidinium group in STX, as well as at the TTX 7,8,9-guanidinium group. Addition of explicit water molecules around the toxins is shown to have no significant impact on the charge distribution pattern (see Supplementary Fig. S1). The increased positive charge at the imidazole guanidinium groups observed in our fully protonated models of both STX and TTX, matches with the proposed mechanism of enhanced 
molecular toxicity ${ }^{24}$. The increased relative proportion of active toxin, combined with a slower degradation rate of TTX in lower $\mathrm{pH}$ conditions ${ }^{27}$ and minimal $\mathrm{pH}$-effects on the receptors in the $\mathrm{pH}$ range of ocean acidification $^{28}$, suggests a significantly increased bioavailability of these keystone molecules, and thus a significant increase of their toxicity, in future oceans.

To visualise the increased abundance of protonated toxic forms of STX in the ocean at a global scale we produced geospatial maps for current (Fig. 2a) and future oceanic $\mathrm{pH}$ and sea surface temperature conditions (Fig. 2b) based on the IPCC RCP8.5 business-as-usual scenario ${ }^{1}$. The absolute change between present and future protonated, toxic saxitoxin abundance in \% is depicted in Figure 2c. The global model for present conditions shows higher levels of protonated STX, and thus greater bioavailability of the toxic form in seawater towards the poles (see also Supplementary Fig. S2). These increased levels of the more toxic form of STX will in the future extend towards the equator, with the Eurasian coastline of the Arctic circle reaching very high levels. The results reveal and pinpoint five "hotspots" where we predict future bioavailability of toxic STX to be significantly increased (Fig 2c): (i) the North-West Coast of the U.S.A., (ii) the Arctic Circle where Alexandrium tamarense blooms have already become more frequent due to warming climate ${ }^{29}$, (iii) the mid-Atlantic Ridge, (iv) the Indian Ocean, and lastly and perhaps most unexpectedly (v) the Coral and Solomon Seas between North-East Australia and the Solomon Islands. Gymnodinium and Alexandrium species have been recorded a little further south between Coral and Tasman Seas $^{30}$, but any global-warming induced range shifts of these taxa ${ }^{31}$ could potentially lead to devastating PSP-related future HABs as indicated by current HABs around Papua New Guinea caused by the related STX-producing Pyrodinium bahamense ${ }^{32}$.

The future increase of active toxin forms predicted by our geospatial interpolation models (Fig. 2) is relative to the total amount of toxin present. Combining this proportional increase in toxicity with the projected increases in $\mathrm{HAB}$ duration, intensity ${ }^{17}$ and actual higher toxin production within the cells ${ }^{33}$ could result in devastating effects on marine fisheries, tourism, coastal ecosystems, and public health ${ }^{21}$, especially once the toxins are released during HAB termination. The increase in protonated and therefore toxic forms also extends to a multitude of STX derivatives produced by HAB forming algae that vary with local environmental conditions ${ }^{34}$, as all main STX derivatives share the 7,8,9-guanidinium group and therefore increase in their toxicity like STX does (see Table 1 and Supplementary Table 1).

Recent years have seen rising numbers of STX-related PSP recordings from cold northern waters ${ }^{19,35}$, such as the Barents Sea where the STX producing Alexandrium tamarense occurs ${ }^{36}$. In these areas, algal toxins, in particular STX, were identified in ten out of 13 marine stranded or harvested mammal species ${ }^{35}$, including humpback and bowhead whales, seals and sea otters. Since many of these affected mammals prey upon filter feeders such as the Alaskan butter clam (Saxidomus gigantea), a species also frequently consumed by 
the local people, an increase in toxicity as indicated by our maps for this region would have even more devastating direct implications.

We therefore applied our model to calculate the projected toxicity at the end of this century using current STX contents determined in butter clams collected from an affected area and found that the amount of toxic STX in butter clams from Alaska will increase in the future to levels exceeding the current US Food and Drug Administration (FDA) limit, putting marine predators and food security at risk (Fig. 3). To maintain the current recommendations for seafood safety in the future (RCP8.5 conditions), the FDA limit of 80 $\mu \mathrm{g} / 100 \mathrm{~g}$ total saxitoxin in tissue, which equals $50.4 \mu \mathrm{g} / 100 \mathrm{~g}$ of toxic STX form (Fig. 3), will need to be reduced by over $20 \%$ to $62.8 \mu \mathrm{g} / 100 \mathrm{~g}$ of total saxitoxin. Despite seasonal variability with clear saxitoxin summer peaks (see Supplementary Fig. S3) all butter clam samples taken since May 2014 already exceed the current FDA limit (Fig. 3b). In combination with projected increases of total STX concentration released by HABs in future ocean conditions ${ }^{32}$, our estimates made here for future STX toxicity may even be exceeded.

The most-impacted areas also encompass the Great Barrier Reef and the Solomon Islands (Fig 2c), where organisms ranging from dinoflagellates to worms, blue ring octopuses and pufferfish use STX and TTX as signalling molecules for key ecological functions ${ }^{14}$. Both toxins play a vital role in species interactions, such as deterring potential predators, attracting potential mates or serving as venom to overcome larger prey $^{14}$. An imbalance of these interactions caused by altered effectiveness of these signalling molecules could significantly impact the ecological network. Many other biomolecules used by marine organisms to communicate have $\mathrm{pH}$-sensitive chemical groups similar to the guanidinium groups shown here for TTX and $\mathrm{STX}^{9}$ and are likely to be altered by future climate change. This impact of $\mathrm{pH}$ can further be expected to apply not only to biomolecules but virtually any molecule dissolved in the sea that can be protonated, from marine drugs to man-made pollutants, such as pharmaceuticals, pesticides or plasticisers. However, the responses of marine organisms under future ocean conditions can be variable ${ }^{8}$, and difficult to predict owing to species specific differences and their potential for adaptation. A better understanding of the impacts of $\mathrm{pH}$ and temperature on chemicals used by marine organisms is urgently needed to assess the full risk for marine life in changing oceans. 
Correspondence and requests for materials should be addressed to Dr. C.C. Roggatz.

\section{Acknowledgements}

We acknowledge the Viper High Performance Computing facility of the University of Hull and its support team. CCR was funded through Prof. D. Parsons' ERC-2016-COG GEOSTICK project grant. We thank the Quagan Tayagungin Tribe for access to the clam toxicity data at the PSP Program website. We acknowledge the World Climate Research Programme's Working Group on Coupled Modelling and the climate modelling groups, for producing and making available their model output. For CMIP the U.S. Department of Energy's Program for Climate Model Diagnosis and Inter-comparison provides coordinating support and led the development of software infrastructure in partnership with the Global Organization for Earth System Science Portals. We thank Professor D. Parsons, Energy and Environment Institute/University of Hull and Dr. H. Bartels-Hardege, Biological and Marine Sciences/ University of Hull for valuable suggestions and discussions.

\section{Author contributions}

CCR and JDH designed the study, KCWV and ACA performed the analysis of the datasets for geospatial models, and $\mathrm{CCR}$ and DMB calculated the molecular models. Access to toxin mussel data were provided by AD and BW. CCR, JDH, KCWV shared responsibility for, and NF contributed to the writing of the manuscript. All authors contributed to the final version of the manuscript.

\section{Competing interests}

The authors declare no competing interests.

\section{References}

1. $\quad$ Core Writing Team, R. K. Pachauri and L. A. Meyer (eds.). IPCC, 2014: Climate change 2014: Synthesis Report. Contribution of Working Groups I, II and III to the Fifth Assessment Report of the Intergovernmental Panel on Climate Change. (IPCC, Geneva, Switzerland, 2014).

2. DeWeerdt, S. Sea change. Nature 550, S54-S58 (2017).

3. Ferrer, R. P. \& Zimmer, R. K. Molecules of keystone significance: Crucial agents in ecology and resource management. Bioscience 63, 428-438 (2013).

4. Caldeira, K. \& Wickett, M. E. Oceanography: anthropogenic carbon and ocean pH. Nature 425, 365 (2003).

5. Baumann, H. \& Smith, E. M. Quantifying metabolically driven $\mathrm{pH}$ and oxygen fluctuations in US 
nearshore habitats at diel to interannual time scales. Estuaries Coasts 41, 1102-1117 (2018).

6. Fabry, V. J., Seibel, B. A., Feely, R. A. \& Orr, J. C. Impacts of ocean acidification on marine fauna and ecosystem processes. ICES J. Mar. Sci. 65, 414-432 (2008).

7. Wittmann, A. C. \& Pörtner, H.-O. Sensitivities of extant animal taxa to ocean acidification. Nat. Clim. Chang. 3, 995 (2013).

8. Clements, J. C. \& Hunt, H. L. Marine animal behaviour in a high $\mathrm{CO}_{2}$ ocean. Mar. Ecol. Prog. Ser. 536, 259-279 (2015).

9. Roggatz, C. C., Lorch, M., Hardege, J. D. \& Benoit, D. M. Ocean acidification affects marine chemical communication by changing structure and function of peptide signalling molecules. Glob. Chang. Biol. 22, 3914-3926 (2016).

10. Porteus, C. S. et al. Near-future $\mathrm{CO}_{2}$ levels impair the olfactory system of a marine fish. Nat. Clim. Chang. 8, 737-743 (2018).

11. Hay, M. E. Marine chemical ecology: chemical signals and cues structure marine populations, communities, and ecosystems. Ann. Rev. Mar. Sci. 1, 193-212 (2009).

12. Bane, V., Lehane, M., Dikshit, M., O’Riordan, A. \& Furey, A. Tetrodotoxin: chemistry, toxicity, source, distribution and detection. Toxins 6, 693-755 (2014).

13. Cusick, K. D. \& Sayler, G. S. An overview on the marine neurotoxin, saxitoxin: genetics, molecular targets, methods of detection and ecological functions. Mar. Drugs 11, 991-1018 (2013).

14. Williams, B. L. Behavioral and chemical ecology of marine organisms with respect to tetrodotoxin. Mar. Drugs 8, 381-398 (2010).

15. Wyatt, T. \& Jenkinson, I. R. Notes on Alexandrium population dynamics. J. Plankton Res. 19, 551575 (1997).

16. Lefebvre, K. A. et al. Characterization of intracellular and extracellular saxitoxin levels in both field and cultured Alexandrium spp. samples from Sequim Bay, Washington. Mar. Drugs 6, 103-116 (2008).

17. Gobler, C. J. et al. Ocean warming since 1982 has expanded the niche of toxic algal blooms in the North Atlantic and North Pacific oceans. Proc. Natl. Acad. Sci. U. S. A. 114, 4975-4980 (2017). 
18. Riebesell, U. et al. Toxic algal bloom induced by ocean acidification disrupts the pelagic food web. Nat. Clim. Chang. 8, 1082-1086 (2018).

19. Li, A., Chen, H., Qiu, J., Lin, H. \& Gu, H. Determination of multiple toxins in whelk and clam samples collected from the Chukchi and Bering seas. Toxicon 109, 84-93 (2016).

20. Starr, M. et al. Multispecies mass mortality of marine fauna linked to a toxic dinoflagellate bloom. PLoS One 12, e0176299 (2017).

21. Wang, D.-Z. Neurotoxins from marine dinoflagellates: a brief review. Mar. Drugs 6, 349-371 (2008).

22. Woodward, R. B. The structure of tetrodotoxin. J. Macromol. Sci. Part A Pure Appl. Chem. 9, (1964).

23. Rogers, R. S. \& Rapoport, H. The $\mathrm{p} K_{a}$ s of saxitoxin. J. Am. Chem. Soc. 102, 7335-7339 (1980).

24. Hegyi, B. et al. Tetrodotoxin blockade on canine cardiac L-type $\mathrm{Ca}^{2+}$ channels depends on $\mathrm{pH}$ and redox potential. Mar. Drugs 11, 2140-2153 (2013).

25. Yotsu-Yamashita, M., Sugimoto, A., Takai, A. \& Yasumoto, T. Effects of specific modifications of several hydroxyls of tetrodotoxin on its affinity to rat brain membrane. J. Pharmacol. Exp. Ther. 289, 1688-1696 (1999).

26. Roggatz, C. C., Lorch, M. \& Benoit, D. M. Influence of Solvent Representation on Nuclear Shielding Calculations of Protonation States of Small Biological Molecules. J. Chem. Theory Comput. 14, 2684-2695 (2018).

27. Colquhoun, D., Henderson, R. \& Ritchie, J. M. The binding of labelled tetrodotoxin to nonmyelinated nerve fibres. J. Physiol. 227, 95-126 (1972).

28. Ulbricht, W. \& Wagner, H. H. The influence of $\mathrm{pH}$ on the rate of tetrodotoxin action on myelinated nerve fibres. J. Physiol. 252, 185-202 (1975).

29. Natsuike, M. et al. Possible spreading of toxic Alexandrium tamarense blooms on the Chukchi Sea shelf with the inflow of Pacific summer water due to climatic warming. Harmful Algae 61, 80-86 (2017).

30. Blackburn, S. I., Hallegraeff, G. M. \& Bolch, C. J. Vegetative reproduction and sexual life cycle of 
the toxic dinoflagellate Gymnodinium catenatum from Tasmania, Australia. J. Phycol. 25, 577-590 (1989).

31. Hallegraeff, G. M. Ocean climate change, phytoplankton community responses, and harmful algal blooms: a formidable predictive challenge. J. Phycol. 46, 220-235 (2010).

32. Hallegraeff, G. M. A review of harmful algal blooms and their apparent global increase. Phycologia 32, 79-99 (1993).

33. Tatters, A. O., Flewelling, L. J., Fu, F., Granholm, A. A. \& Hutchins, D. A. High $\mathrm{CO}_{2}$ promotes the production of paralytic shellfish poisoning toxins by Alexandrium catenella from Southern California waters. Harmful Algae 30, 37-43 (2013).

34. Cembella, A. Ecophysiology and Metabolism of Paralytic Shellfish Toxins in Marine Microalgae. Physiological Ecology of Harmful Algal Blooms, Springer-Verlag, Heidelberg, Anderson, D.M., A.D. Cembella, G.M. Hallegraeff (Eds.), NATO-Advanced Study Institute Series 41, 381-404 (1998).

35. Lefebvre, K. A. et al. Prevalence of algal toxins in Alaskan marine mammals foraging in a changing arctic and subarctic environment. Harmful Algae 55, 13-24 (2016).

36. Zonneveld, K. A. F. et al. Atlas of modern dinoflagellate cyst distribution based on 2405 data points. Rev. Palaeobot. Palynol. 191, 1-197 (2013). 


\section{FIGURES}

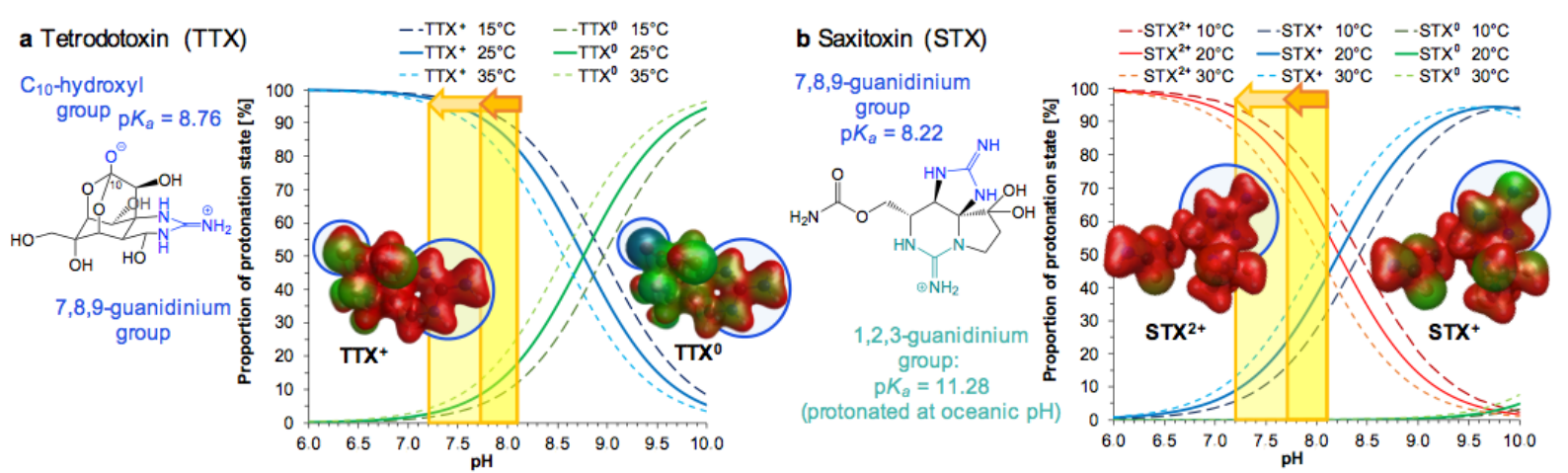

Figure 1: Neurotoxin structures, charge distributions and relative proportions of individual protonation states. a Tetrodotoxin (TTX) and b Saxitoxin (STX). The chemical structures (left) with highlighted ionisable groups are annotated with the respective $\mathrm{p} K_{a}$ values. In the proportion plots, blue (TTX) and red (STX) continuous lines represent the active toxin form abundance based on literature $\mathrm{p} K_{a}$ at $25^{\circ} \mathrm{C}(\mathrm{TTX}) / 20^{\circ} \mathrm{C}(\mathrm{STX})$. The other continuous lines represent the forms with non-protonated 7,8,9-guanidinium group (green in TTX, blue in STX) and deprotonated 1,2,3-guanidinium group (green in STX). The dashed lines represent the proportions within an envelope of $\pm 10^{\circ} \mathrm{C}$ around the temperature of $\mathrm{p} K_{a}$ determination $\left(+10^{\circ} \mathrm{C}-\right.$ short dashes; $-10^{\circ} \mathrm{C}-$ long dashes $)$. The increase in toxic TTX and STX forms for the expected change in $\mathrm{pH}$ with ocean acidification from 8.1 to 7.7 in the year 2100 (dark yellow) and the change in $\mathrm{pH}$ from 8.1 to 7.2 already observed temporarily in coastal estuarine areas is highlighted by the yellow shaded areas and arrows (middle). Computationally optimised conformations (PBE0/pc-2) of the non- or partly protonated forms $\left(\mathrm{TTX}^{0}\right.$ and $\left.\mathrm{STX}^{+}\right)$and fully protonated toxic forms $\left(\mathrm{TTX}^{+}\right.$and $\mathrm{STX}^{2+}$ ) are shown with their electrostatic potential values mapped onto an electron density iso-surface. Blue indicates negative, green neutral and red positive charge. Chemical groups changing electrostatic potential are circled. 


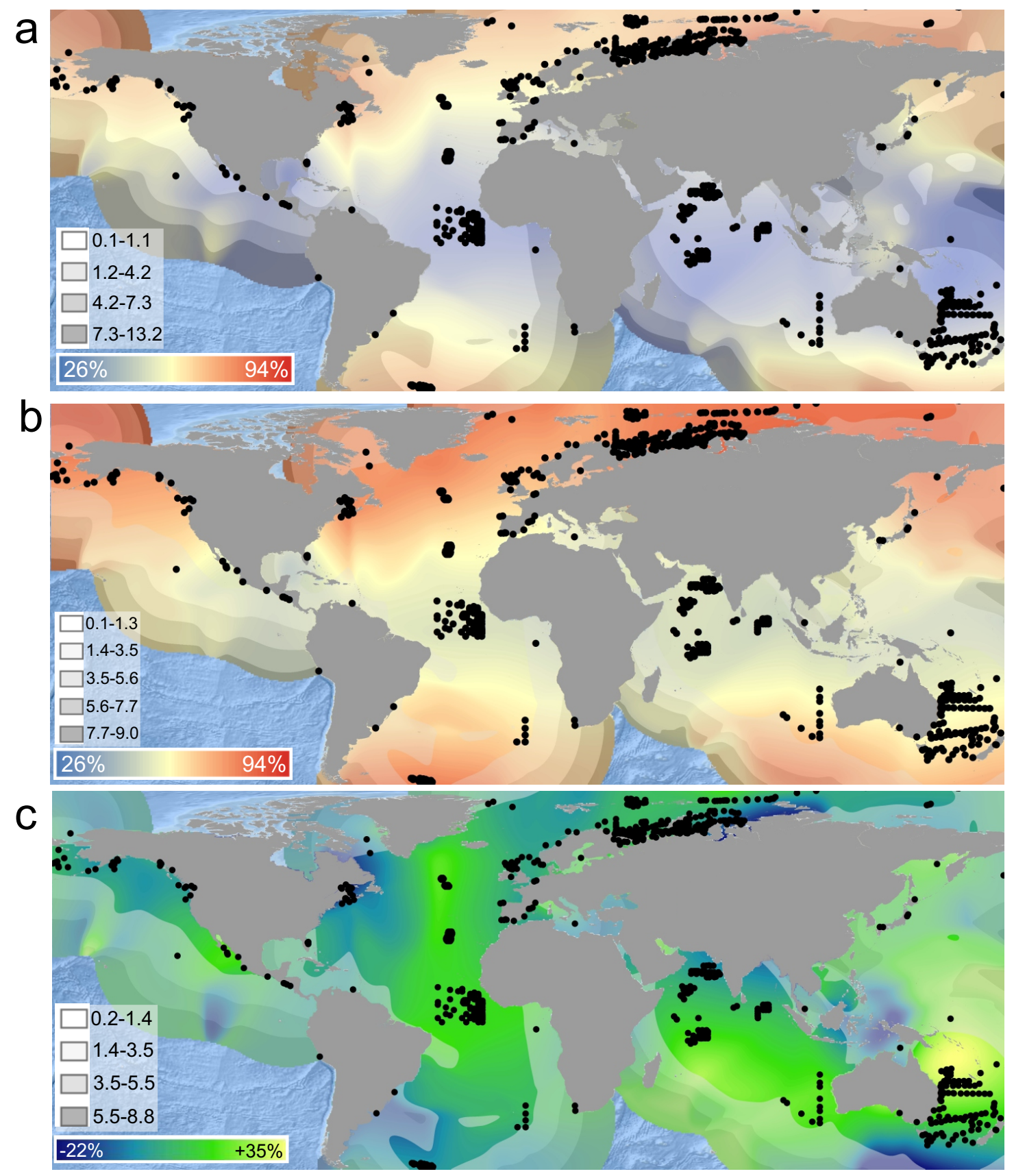

Figure 2: Global abundance of the toxic saxitoxin protonation state today and in the future. Abundance expressed in \% shown for a today, $\mathbf{b}$ in 2100 , and $\mathbf{c}$ as their difference. Kernel density-estimated spatial distribution maps based on concatenated records of saxitoxin-producing HABs with PSP and planktonic sampling-based occurrence records of Gymnodinium and Alexandrium dinoflagellates (black dots). a Current mean sea surface temperature and current sea surface $\mathrm{pH}$ (including freshwater influx); b under RCP8.5 estimated 2061-2100 sea surface $\mathrm{pH}$ and 2087-2096 predicted average sea surface temperatures; $\mathbf{c}$ absolute differences in protonation state between $\mathbf{a}$ and $\mathbf{b}$ (zero change corresponds to dark green colour). Note that $\mathbf{b}$ does not incorporate estimates of freshwater influx present in a and so might underestimate protonation state in coastal areas. Model uncertainty (the spatial distribution of the standard error of prediction in percent, white box) is visualized as units of its standard deviation in form of grey shaded bands from transparent to dark. 


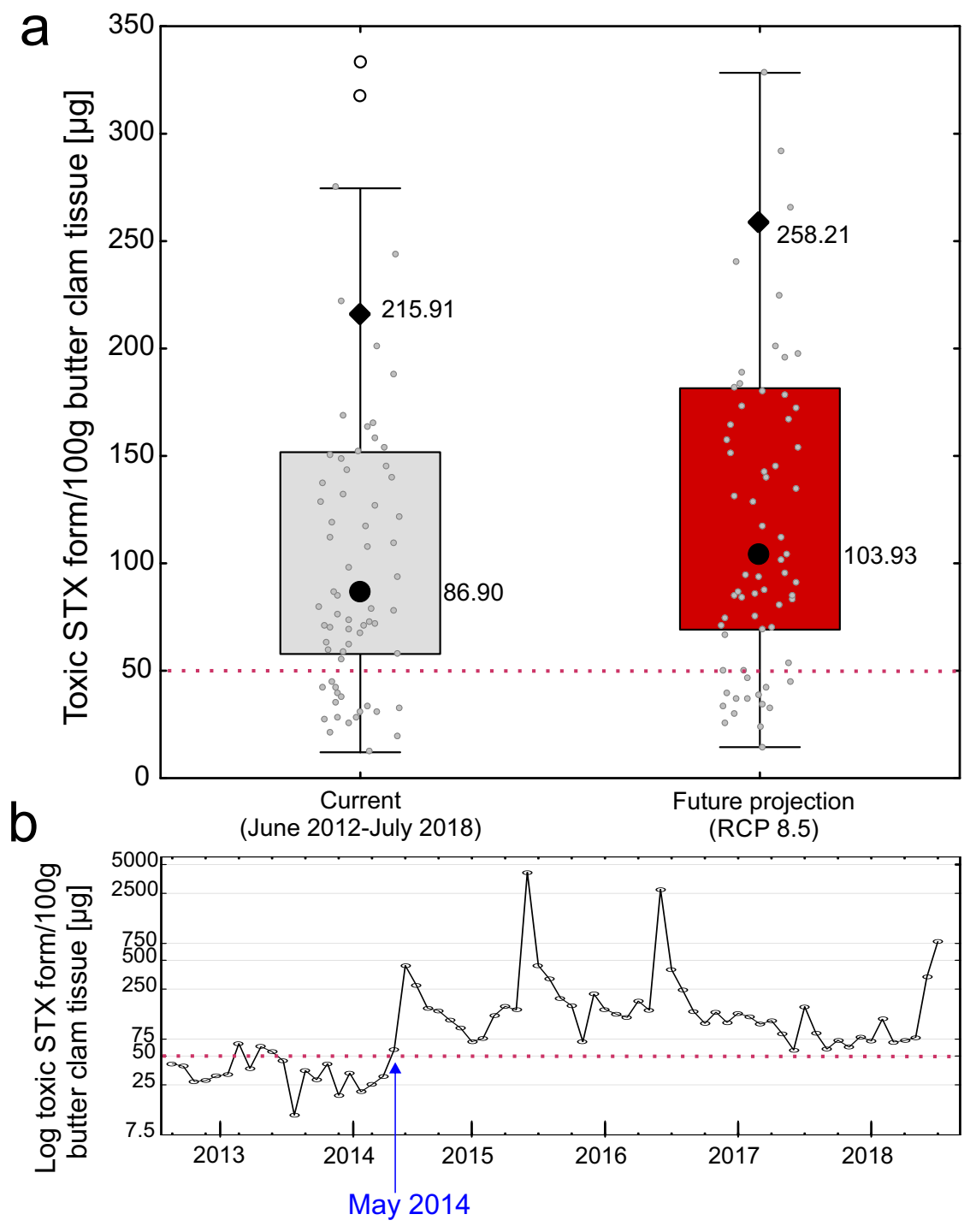

Figure 3: Amount of the toxic saxitoxin form present in butter clam Saxidomus gigantea tissue. Data based on $100 \mathrm{~g}$ butter clam tissue from Sand Point's Spit Beach, Alaska over the past six years ( $\mathrm{n}=73 \mathrm{each}$, monthly data points). Shown in a are values (small circles) based on current (left, grey) and estimated future (RCP8.5; right, red) Kernel interpolation values (see Fig. 2); the latter based on the assumption of constant amount of overall toxin and dinoflagellate abundance (values are displayed up to $350 \mu \mathrm{g} / 100 \mathrm{~g}$ ). Large filled circles (and boxes) display the median values, diamonds are arithmetic means, and whiskers show non-outlier range. The amount of toxic STX in clam tissue over the past five years is shown in $\mathbf{b}$. The red dashed line indicates the amount of toxic STX form $(50.4 \mu \mathrm{g} / 100 \mathrm{~g})$ that equals the current US Food and Drug Administration (FDA) limit of $80 \mu \mathrm{g} / 100 \mathrm{~g}$ total STX in seafood tissue under today's conditions. Additional outliers (open circles) and extreme values range to $6,580 \mu \mathrm{g} / 100 \mathrm{~g}$ not displayed in a are shown in b. The monthly toxic STX content in clam tissue ranged less than the current FDA limit last in May 2014. 


\section{TABLES}

Table 1: Change in abundance of TTX, STX and saxitoxin derivatives in future and coastal oceanic $\mathrm{pH}$ conditions.

\begin{tabular}{|c|c|c|c|c|c|}
\hline \multirow{2}{*}{ Compound } & \multirow{2}{*}{$\begin{array}{l}\mathrm{p} K_{a} \\
\text { values }^{\mathrm{a}}\end{array}$} & \multicolumn{4}{|c|}{ Change in abundance of protonated, toxic form(s) } \\
\hline & & $\begin{array}{l}\text { Average } \mathrm{pH} \\
\text { change } \\
8.1 \rightarrow 7.7 \\
(\text { constant } \mathrm{T})^{\mathrm{b}}\end{array}$ & $\begin{array}{l}\text { Coastal } \mathrm{pH} \\
\text { change } \\
8.1 \rightarrow 7.2 \\
(\text { constant } \mathrm{T})^{\mathrm{b}}\end{array}$ & $\begin{array}{l}\text { RCP } 8.5 \text { average } \\
\text { scenario }^{c}: p H \\
8.1 \rightarrow 7.7 \text { and SST } \\
16.1 \rightarrow 20.1^{\circ} \mathrm{C}\end{array}$ & $\begin{array}{l}\text { RCP8.5 for coastal } \\
\text { areas }^{\mathrm{c}}: \mathrm{pH} 8.1 \rightarrow 7.2 \\
\text { and SST } \\
16.1 \rightarrow 20.1^{\circ} \mathrm{C}\end{array}$ \\
\hline TTX & 8.76 & $+9.9 \%$ & $+15.3 \%$ & $+6.2 \%$ & $+10.5 \%$ \\
\hline STX & $\begin{array}{l}8.22 ; \\
11.28\end{array}$ & $+20.0 \%$ & $+34.4 \%$ & $+15.5 \%$ & $+30.1 \%$ \\
\hline $\begin{array}{l}\text { STX with } \\
0.1 \mathrm{M} \mathrm{KCl}\end{array}$ & $\begin{array}{l}8.39 \\
11.30\end{array}$ & $+17.0 \%$ & $+27.8 \%$ & $+13.0 \%$ & $+23.9 \%$ \\
\hline dcSTX & $\begin{array}{l}8.10 \\
10.48\end{array}$ & $+21.5 \%$ & $+38.8 \%$ & $+17.0 \%$ & $+34.4 \%$ \\
\hline neoSTX & $\begin{array}{l}6.75 \\
8.65 \\
11.65\end{array}$ & $+12.1 \%$ & $+22.2 \%$ & $+9.1 \%$ & $+15.7 \%$ \\
\hline
\end{tabular}

${ }^{\mathrm{a}} \mathrm{p} K_{a}$ constants from experimental titration of TTX at $25^{\circ} \mathrm{C}$ and STX and its derivatives at $20^{\circ} \mathrm{C}$; for references see methods. ${ }^{\mathrm{b}}$ Differences calculated at the respective temperature of $\mathrm{p} K_{a}$ determination. ${ }^{\mathrm{c}}$ Sea surface temperature (SST) based on current global annual average $\left(16.1^{\circ} \mathrm{C}\right)$ and future increase by $4^{\circ} \mathrm{C}$ under the RCP8.5 $\left(20.1{ }^{\circ} \mathrm{C}\right.$ ), included as $\mathrm{p} K_{a}$-influencing factor of $-0.02 \mathrm{per}+1{ }^{\circ} \mathrm{C}$ (see methods for calculation details). 


\section{Methods}

\section{Calculation of protonation state abundance}

Different protonation states of a molecule are present at different $\mathrm{pH}$ conditions. The $\mathrm{pH}$ at which $50 \%$ of a given ionisable group are protonated and $50 \%$ remain unchanged is given by a group-specific $\mathrm{p} K_{a}$ value, which can be determined by potentiometric or NMR-based titration. ${ }^{37}$ For tetrodotoxin (TTX), Goto et al. ${ }^{38}$ obtained a $\mathrm{p} K_{a}$ of 8.76 at room temperature $\left(25^{\circ} \mathrm{C}\right)$ through multiple potentiometric titrations. For saxitoxin, Rogers \& Rapoport ${ }^{39}$ found the $\mathrm{p} K_{a}$ values of the ionisable 7,8,9- and 1,2,3-guanidinium groups to be 8.22 and 11.28 at $20^{\circ} \mathrm{C}$, respectively. When performed in $0.1 \mathrm{M} \mathrm{KCl}$ the potentiometric titrations yielded $\mathrm{p} K_{a}$ values of 8.39 and $11.30\left(20^{\circ} \mathrm{C}\right)$ for these groups ${ }^{39}$. The $\mathrm{p} K_{a}$ values of common saxitoxin derivatives were established as 8.10 and 10.48 for $\mathrm{dcSTX}^{39}$ and as $6.75,8.65$ and 11.65 for neoSTX ${ }^{40}\left(20^{\circ} \mathrm{C}\right)$. Based on the literature $\mathrm{p} K_{a}$ values, the concentration and therefore abundance of each protonation state over the $\mathrm{pH}$ range was calculated using the Henderson-Hasselbalch equation that relates the $\mathrm{pH}$ to the $\mathrm{p} K_{a}$ (for details see Po \& Senozan ${ }^{41}$ and references therein). Results are shown in Figure 1. Temperature was incorporated as a factor influencing the $\mathrm{p} K_{a}$ constants by -0.02 units for $+1{ }^{\circ} \mathrm{C}$. This factor has been established for primary amine groups, similar to the guanidinium groups in TTX and STX, by Reijenga et al. ${ }^{42}$. It was used here to calculate the data plotted for the $\pm 10^{\circ} \mathrm{C}$ curves framing the abundance curves calculated at the respective titration temperatures $\left(25^{\circ} \mathrm{C}\right.$ for TTX, $20^{\circ} \mathrm{C}$ for STX) in Fig. 1, because experimental $\mathrm{p} K_{a}$ values determined at other temperatures are not available. The changes in abundance of the protonated, toxic forms in Table 1 were calculated based on the same $\mathrm{p} K_{a}$ values. Differences between current and future/coastal $\mathrm{pH}$ conditions $(\mathrm{pH} 8.1 \rightarrow 7.7 / 7.2)$ were either calculated at constant temperature $\left(25 / 20^{\circ} \mathrm{C}\right)$, depending on the temperature at which the respective literature $\mathrm{p} K_{a}$ values were determined, or under the RCP 8.5 scenario $^{43}$ where temperature changes were taken into account by employing the above described $\mathrm{p} K_{a}$-influencing temperature factor. For the RCP8.5 scenario we assumed global annual average ocean sea surface temperature $\left(16.1^{\circ} \mathrm{C}\right)^{44}$ and average $\mathrm{pH} 8.1$ for current conditions and $\mathrm{pH} 7.7$ (average)/ $\mathrm{pH} 7.2$ (coastal) combined with a $4^{\circ} \mathrm{C} \mathrm{SST}$ increase to average $20.1^{\circ} \mathrm{C}$ for future conditions (RCP8.5). In coastal areas pH 7.2 is already observed temporarily ${ }^{45}$ and is likely to become more frequent in the future.

\section{Optimisation of protonation state conformers}

A change in protonation states of these molecules could be accompanied by structural changes to the cues in the lowered $\mathrm{pH}$ of future oceans. To investigate this, we used quantum chemical calculations to obtain the energetically most favourable conformers for each possible protonation state. These model conformers were then used to assess conformational differences between the protonation states, as well as differences in their molecular electrostatic potential (MEP), which describes the charge distribution around the molecule. Starting from the plain structure SMILES code of TTX and STX (PubChem ${ }^{46}$ CID $=11174599^{47}$ and $\mathrm{CID}=37165^{48}$ ), protons were added/removed according to the protonation state structures proposed by 
Mosher ${ }^{49}$ for TTX (with the dissociating proton located at the hydroxyl group of C-10, not at the 7,8,9guanidinium group) and Shimizu et $a l^{40}$ for STX. Then conformers were optimized using the PBE0 exchange correlation functional ${ }^{50}$ with a pc-2 basis $\operatorname{set}^{51-53}$ and water as implicit solvent using $\operatorname{COSMO}^{54}$ implemented in the ORCA suite of programs $^{55}$ (Version 3.0.0). We used the RIJ-COSX approximation ${ }^{56}$ with a def2-TZVPP/J auxiliary basis set ${ }^{57}$ and included D3 dispersion corrections following Grimme et al. ${ }^{58}$ The VeryTightSCF and TightOpt criteria implemented in ORCA were used to stop the SCF gradient and the optimization at a total energy change of $<10^{-8} \mathrm{E}_{\mathrm{h}}$, respectively. Differences of conformers between protonation states were assessed by calculation of the root-mean square deviation (RMSD) of atom coordinates after normalisation with respect to the position of $\mathrm{C}_{1}$.

\section{Calculation and visualisation of the charge distribution}

The calculation of the molecular electrostatic potential (MEP) was performed with the GAMESS program (vJan122009R1) using the PBE0 exchange correlation functional ${ }^{50}$ in conjunction with a pc-2 basis set ${ }^{51-}$

${ }^{53}$. A three-dimensional electron density iso-surface was visualized with 100 grid points, a medium grid size and a contour value of $0.03 \mathrm{e} \cdot \mathrm{a}_{0}{ }^{-3}$ using the wxMacMolPlt program ${ }^{59}$ (v7.5141). The density iso-surface was coloured according to the MEP with a maximum value of $0.25 \mathrm{E}_{\mathrm{h}} \mathrm{e}^{-1}$ and the RGB colour scheme with red representing positive, green neutral and blue negative charge.

\section{Interpolation maps for spatial prediction of protonation state}

In order to visualize the spatial distribution of the current protonation levels of saxitoxin as well as the effect of future changing oceanic $\mathrm{pH}$ and predicted increase of sea surface temperature on these, we generated Kernel interpolation maps with standard error for current and future predicted protonation states in ArcMap (V10.5.1) based on 6485 global occurrence records of saxitoxin-related PSP HABs and HAB causing dinoflagellates Gymnodinium and Alexandrium.

These occurrence records for paralytic shellfish poisoning were obtained from the Harmful Algal Information System metadatabase (HAEDAT, http:/haedat.iode.org). From this metadatabase, we selected records for HAB (Harmful Algal Blooms) involving PSP (Paralytic Shellfish Poisoning) and filtered these records for proven presence of saxitoxin. We obtained 138 unique georeferenced records for localities with STX-related HABs. Additionally, we obtained 6347 records for the distribution of two dinoflagellate genera, which are known to produce STX, Gymnodinium and Alexandrium, from the NOAA COPEPOD database. The data has been generated from 1954-1999 scientific plankton sampling expeditions. These records were likewise curated and verified by hand. Together, this gives a first, coarse estimate for the global distribution of STX-producing marine dinoflagellates.

In order to visualise future changes in estimated toxicity, we obtained raster data of current and future $\mathrm{pH}$ (measured as the acidity of the ocean surface), and current and future mean sea surface temperature SSH (measured as the water temperature at the ocean surface within the topmost meter of the water column in 
$\left.{ }^{\circ} \mathrm{C}\right)$. Current $\mathrm{pH}$ and current as well as future (2100) SST were obtained from GMED $\left(\mathrm{V} 1.0^{60}\right)$. Within this data set, the current pH layer was sourced from 1961-2009 WOD in situ measurements based on Surface Ocean Station Data (OSD), and High-resolution Conductivity-Temperature-Depth (CTD) ${ }^{61}$. The SST layers were sourced from remote-sensing data (Remote Sensing: Aqua-MODIS) between 2002-2009 in 5 arcmin resolution (originally published as the Bio-Oracle dataset ${ }^{62}$ ). Future SST (in ${ }^{\circ} \mathrm{C}$ ) was obtained in form of future 4 grids of monthly mean sea surface temperature, A1B (720 ppm stabilization) scenario modelled under UKMO-HadCM3 predicted for the period 2087-2096 (originally published in Bio-Oracle ${ }^{62}$ ). The original data source was the IPCC (WCRP CMIP3) multi-model database (https://cmip.llnl.gov). Future $\mathrm{pH}$ data was also obtained from the IPCC (WCRP CMIP3) multi-model database for the Representative Concentration Pathway RCP8.5 (Norwegian climate centre dataset) representing the current trajectory of business-as-usual $\mathrm{CO}_{2}$ emissions $^{63}$. An ocean basemap layer was obtained from ESRI (2014) ${ }^{64}$.

To model spatial relationships between layers, the Geostatistical Analyst toolkit was used in ArcMap. As the data is modelled within the ocean, a world vector shorelines shapefile (GSHHS_c_L1 containing all continents except Antarctica, crude shoreline) was obtained from NOAA to serve as a barrier feature. Current and future STX protonation states were calculated for all 6485 point locations based on the locationspecific current/ future $\mathrm{pH}$ and sea surface temperature GIS layers. Subsequently, exploratory interpolation models were generated using Kernel Interpolation with Barriers under the fifth polynomial kernel model and default settings otherwise. For final interpolation models, six additional data points were added for current and future $\mathrm{pH}, \mathrm{SST}$, and estimated STX toxicity at (61.856, -57.609122), (66.964957, -58.86248), (23.66196, -128.964261), (-3.666003, 3.57050), (-10.559389, 138.745221), and (0.289336, 157.401397).

Though there were no HAB or dinoflagellate records at these six coordinates, they were located in an area of high current $\mathrm{pH}$ turnover and thus proved helpful to yield a more reliable interpolation model. Their location is also indicated with high model uncertainty, reflecting their substituted nature.

\section{Calculation of future toxicity of STX in clam tissue and FDA limit}

The saxitoxin content in $\mu \mathrm{g} / 100 \mathrm{~g}$ clam tissue was extracted from the PSP Program website of the Quagan Tayagungin Tribe ${ }^{65}$ for the time frame between June 2012 and July 2018 for each month and averaged annually. The proportions of toxic STX form at current conditions $(\mathrm{pH}, \mathrm{T})$ as well as the future RCP8.5 scenario were extracted from the interpolation maps for the closest location to Spit Beach, Sand Point (Alaska), respectively. It was assumed that internal clam $\mathrm{pH}$ was close to the environmental $\mathrm{pH}$ due to the limited ability of bivalves to regulate their internal $\mathrm{pH}^{66-68}$. The proportional data was then used to calculate the amount of toxic STX in $\mu \mathrm{g} / 100 \mathrm{~g}$ clam tissue today and assuming the two future scenarios. It illustrates how the content of toxic STX in shellfish would be affected by future conditions (Fig. 3). We further calculated the amount of toxic STX currently present at the limit of $80 \mu \mathrm{g} / 100 \mathrm{~g}$ clam tissue set by the US Food and Drug Administration (FDA) ${ }^{69}$, which is seen as safe to consume, and included it in Fig. 3. 


\section{Data availability}

Source data for curves in Fig. 1 calculated based on the given references and coordinates of the molecular structures are available from the corresponding author upon request. The data used to generate the dataset for Fig. 2 are available from the Harmful Algal Information System metadatabase (HAEDAT, http:/haedat.iode.org), the NOAA COPEPOD database (https://www.st.nmfs.noaa.gov/copepod), the Global marine environment dataset (GMED, http://gmed.auckland.ac.nz) and the IPCC (WCRP CMPI3) multi-model database (https://cmip.llnl.gov). Data used to generate Fig. 3 can be accessed via the website of the Qagan Tayagungin Tribe (https://www.qttribe.org >Environment $>$ PSP Program). The extracted, collated data supporting the findings in our study are deposited in the PANGAEA archive and available at https://doi.org/10.1594/PANGAEA.904260.

\section{Code availability}

The code used to calculate the proportions of different protonation states is available on request from the corresponding author.

\section{References (Methods only)}

37. Bezençon, J. et al. $\mathrm{p} K_{a}$ determination by ${ }^{1} \mathrm{H}$ NMR spectroscopy - an old methodology revisited. J. Pharm. Biomed. Anal. 93, 147-155 (2014).

38. Goto, T., Kishi, Y., Takahashi, S. \& Hirata, Y. Tetrodotoxin. Tetrahedron 21, 2059-2088 (1965).

39. Rogers, R. S. \& Rapoport, H. The $\mathrm{p} K_{a}$ s of saxitoxin. J. Am. Chem. Soc. 102, 7335-7339 (1980).

40. Shimizu, Y. et al. Structure of neosaxitoxin. J. Am. Chem. Soc. 100, 6791-6793 (1978).

41. Po, H. N. \& Senozan, N. M. The Henderson-Hasselbalch Equation: Its History and Limitations. J. Chem. Educ. 78, 1499 (2001).

42. Reijenga, J. C., Gagliardi, L. G. \& Kenndler, E. Temperature dependence of acidity constants, a tool to affect separation selectivity in capillary electrophoresis. J. Chromatogr. A 1155, 142-145 (2007).

43. Core Writing Team, R. K. Pachauri and L. A. Meyer (eds.). IPCC, 2014: Climate change 2014: Synthesis Report. Contribution of Working Groups I, II and III to the Fifth Assessment Report of the Intergovernmental Panel on Climate Change. (IPCC, Geneva, Switzerland, 2014). 
44. Sanchez-Lugo. Global Climate Report - Annual 2018 | State of the Climate | National Centers for Environmental Information (NCEI). Available at: https://www.ncdc.noaa.gov/sotc/global/201813. (Accessed: 23rd July 2019)

45. Baumann, H. \& Smith, E. M. Quantifying metabolically driven $\mathrm{pH}$ and oxygen fluctuations in US nearshore habitats at diel to interannual time scales. Estuaries Coasts 41, 1102-1117 (2018). 46. Kim, S. et al. PubChem Substance and Compound databases. Nucleic Acids Res. 44, D1202-13 (2016).

47. National Center for Biotechnology Information. Tetrodotoxin PubChem entry. PubChem Compound Database (2017). Available at: https://pubchem.ncbi.nlm.nih.gov/compound/11174599. (Accessed: 30th January 2017)

48. National Center for Biotechnology Information. Saxitoxin PubChem entry. PubChem Compound Database (2017) Available at: https://pubchem.ncbi.nlm.nih.gov/compound/37165. (Accessed: 30th January 2017)

49. Mosher, H. S. The chemistry of tetrodotoxin. Ann. N. Y. Acad. Sci. 479, 32-43 (1986).

50. Adamo, C. \& Barone, V. Toward reliable density functional methods without adjustable parameters: The PBE0 model. J. Chem. Phys. 110, 6158-6170 (1999).

51. Jensen, F. Polarization consistent basis sets: Principles. J. Chem. Phys. 115, 9113-9125 (2001).

52. Jensen, F. Polarization consistent basis sets. II. Estimating the Kohn-Sham basis set limit. $J$. Chem. Phys. 116, 7372-7379 (2002).

53. Jensen, F. Polarization consistent basis sets. III. The importance of diffuse functions. J. Chem. Phys. 117, 9234-9240 (2002).

54. Klamt, A. Conductor-like Screening Model for Real Solvents: A New Approach to the Quantitative Calculation of Solvation Phenomena. J. Phys. Chem. 99, 2224-2235 (1995).

55. Neese, F. The ORCA program system. Wiley Interdisciplinary Reviews: Computational (2012). 56. Neese, F., Wennmohs, F., Hansen, A. \& Becker, U. Efficient, approximate and parallel HartreeFock and hybrid DFT calculations. A 'chain-of-spheres' algorithm for the Hartree-Fock exchange. Chem. Phys. 356, 98-109 (2009). 
57. Weigend, F. \& Ahlrichs, R. Balanced basis sets of split valence, triple zeta valence and quadruple zeta valence quality for $\mathrm{H}$ to Rn: Design and assessment of accuracy. Phys. Chem. Chem. Phys. 7, 3297-3305 (2005).

58. Grimme, S., Antony, J., Ehrlich, S. \& Krieg, H. A consistent and accurate ab initio parametrization of density functional dispersion correction (DFT-D) for the 94 elements $\mathrm{H}-\mathrm{Pu} . J$. Chem. Phys. 132, 154104 (2010).

59. Bode, B. M. \& Gordon, M. S. MacMolPlt: a graphical user interface for GAMESS. J. Mol. Graph. Model. 16, 133-8, 164 (1998).

60. Basher, Z., Costello, M. J. \& Bowden, D. A. Global marine environment dataset (GMED). World Wide Web electronic publication. Version (2015).

61. Boyer, T. P. et al. World Ocean Database 2013. (2013).

62. Feldman, G. C. \& McClain, C. R. Ocean Color Web, SeaWiFS Reprocessing, NASA Goddard Space Flight Center. Eds. Kuring, N. , Bailey, SW http://oceancolor. gsfc. nasa. gov (2010).

63. Gattuso, J.-P. et al. Contrasting futures for ocean and society from different anthropogenic $\mathrm{CO}_{2}$ emissions scenarios. Science 349, aac4722 (2015).

64. World Ocean Basemap. ESRI Available at: http://services.arcgisonline.com/arcgis/rest/services/Ocean/World_Ocean_Base/MapServer. (Accessed: May 2018)

65. PSP Program. Website of the Quagan Tayagungin Tribe Available at: https://www.qttribe.org/index.asp?Type=B_BASIC\&SEC=\%7B12BC3FE9-E8ED-4E09-B3F66D6254E121B1\%7D. (Accessed: 14th August 2018)

66. Ringwood, A. H. \& Keppler, C. J. Water quality variation and clam growth: Is pH really a nonissue in estuaries? Estuaries 25, 901-907 (2002).

67. Booth, C. E., McDonald, D. G. \& Walsh, P. J. Acid-base balance in the sea mussel, Mytilus edulis. I. Effects of hypoxia and air-exposure on hemolymph acid-base status. Mar. Biol. Lett 5, 347-358 (1984).

68. Dwyer, J. J., Iii \& Burnett, L. E. Acid-Base Status of the Oyster Crassostrea virginica in 
Response to Air Exposure and to Infections by Perkinsus marinus. Biol. Bull. 190, 139-147 (1996).

69. Department of Health and Human Services, Public Health Service, Food and Drug

Administration, Center for Food Safety and Applied Nutrition, Office for Food Safety. Fish and

Fishery Products Hazards and Controls Guidance. (2011). 